Scottish Geographical Journal

\title{
'Stuck Out Here': The Critical Role of Broadband for Remote Rural Places
}

\section{Leanne Townsend, Claire Wallace \& Gorry Fairhurst}

To cite this article: Leanne Townsend, Claire Wallace \& Gorry Fairhurst (2015) 'Stuck Out Here': The Critical Role of Broadband for Remote Rural Places, Scottish Geographical Journal, 131:3-4, 171-180, DOI: 10.1080/14702541.2014.978807

To link to this article: http://dx.doi.org/10.1080/14702541.2014.978807

$$
\begin{aligned}
& \text { (c) } 2015 \text { The Author(s). Published by Taylor \& } \\
& \text { Francis. }
\end{aligned}
$$

\section{曲 Published online: 04 Feb 2015.}

5 Submit your article to this journal $\square$

\section{Џ Article views: 82}

Q View related articles ¿

\section{View Crossmark data $\nearrow$}




\title{
'Stuck Out Here': The Critical Role of Broadband for Remote Rural Places
}

\author{
LEANNE TOWNSEND, CLAIRE WALLACE \& GORRY FAIRHURST \\ dot.rural Digital Economy Hub, University of Aberdeen, Aberdeen, UK
}

(Received 27 March 2014; accepted 16 September 2014)

\begin{abstract}
In a rapidly evolving digital society, broadband connectivity is increasingly critical. Everyday experiences are mediated by technology, be they related to work, education, leisure or health care; technology impacts at many levels. Access to broadband Internet is considered to be essential to contemporary society. Despite this growing recognition, broadband access is still not ubiquitous across all of the UK, with access being particularly problematic in remote rural areas. This paper considers the role of broadband in the economic and social sustainability of remote rural places. During research which explored the use of broadband and its applications amongst small rural business owners located across rural Scotland, qualitative in-depth interviews explored how interviewees used the Internet in the development of and sustainability of their business activities as well as exploring other forms of use such as those relating to education, leisure and social participation. The findings reveal how broadband access and use can impact on rural business owners, and subsequently contribute to the sustainability of life in remote rural Scotland.
\end{abstract}

KEY WORDS: broadband, remote, rural, Scotland, economic, social, sustainability

\section{Introduction}

Remote rural communities suffer disadvantages associated with their distance from urban centres. ${ }^{1}$ Broadband can alleviate these disadvantages by connecting people, places, businesses and services irrespective of the physical location. Broadband use is rapidly becoming integrated into many aspects of everyday life, including banking, shopping, working, studying and social networking. This growing dependence upon the Internet suggests that broadband should be available to all. However, many UK households do not have broadband access of at least 2 megabits per second (Mbps) ${ }^{2}$ - often those living rurally (Ofcom 2011). The most recent report published by Ofcom (the UK Communications regulator) noted that only $80 \%$ of households in the UK have Internet access, although this figure includes those who have chosen not to adopt the technology alongside those who cannot (Ofcom 2013). This problem is not just UK based; many

Correspondence Address: Leanne Townsend, dot.rural Digital Economy Hub, University of Aberdeen, Aberdeen, UK. Email: 1.townsend@abdn.ac.uk 
still lack access across Europe, frequently those in rural areas (European Commission 2009). Despite the efforts of the UK Government (BDUK 2011), the 'digital divide' is widening; as urban areas benefit from ever-improving infrastructure, rural areas more often than not are left behind, leaving them disadvantaged and unable to compete in an increasingly digitally connected commercial world (Townsend et al. 2013).

This growing urban-rural digital divide is of concern to business owners operating in rural areas, who depend on connectivity to network, market their services and reach wider markets (Royal Society of Edinburgh 2010), as well as to participate more broadly in the digital society as individuals and as members of family and community units. Our research is addressing these concerns by exploring potential rural broadband solutions alongside exploring the impact of broadband and its applications for remote rural businesses. The first stage of the research (reported on in this paper) comprised in-depth semi-structured interviews with small to medium-sized enterprises (SMEs) in remote rural areas that could not access adequate broadband services (all interviewees experienced speeds of less than $2 \mathrm{Mbps}$, i.e. speeds consistent with dial-up Internet, and some were unable to access the Internet at all). This paper presents the findings from these interviews, reflecting on the impact of poor connectivity for remote rural economies and communities. The paper is structured as follows: we first discuss relevant literature and research, highlighting pertinent themes. We then present our methodology, following which findings from the qualitative interviews are presented. We conclude by arguing that the critical role of broadband for rural places should be central to policy-making for sustainable rural development.

The paper focuses mostly on business usage of broadband; however, we address issues for business owners in terms of both their business activities and also their personal, family and community activities. This approach reflects our acknowledgement that business owners are embedded in their community and often play an active role within it.

\subsection{The Urban-Rural Digital Divide}

Rural communities can be rich or poor in economic, social and cultural terms (Putnam 1993) and are composed of multiple layers of community with various skills, incomes and social class (Townsend et al. 2014). They often demonstrate strong social capital and creativity (Falk \& Kilpatrick 2000), but many face problems of isolation, accessibilities, depopulation and social cohesion (Townsend et al. 2013). Such problems have often been referred to as the 'rural penalty' (Blanks Hindman 2000), and it is recognised that digital technologies and, in particular, broadband have much to offer in reducing this penalty. Yet paradoxically, access to digital technologies is itself part of the rural penalty faced by rural residents - often such access is poor or even non-existent. The problem is typically more exaggerated in remote and sparsely populated rural regions such as those in central Wales, the Lake District of England, and the Highlands and Islands of south-west Scotland (Royal Society of Edinburgh 2010).

Even where the technology is, or can be made available, the cost to rural consumers of a broadband connection is often higher than it is for those living in urban areas, and rural broadband speeds are typically slower than the UK average (BDUK 2011). Furthermore, due to a lack of competition between Internet Service Providers (ISPs) in many rural areas, consumers often have no or very limited choice of ISP/mobile phone provider because not all operators have nationwide coverage. It is less financially viable for ISPs to offer competitive packages to rural residents, and geographical barriers such as distance 
and small populations mean that ISPs are less likely to roll out new broadband infrastructure such as fibreoptic cables. UK Government is aware of the problem and has committed $£ 530 \mathrm{~m}$ in its endeavour to deliver the best 'Superfast Broadband network in Europe' (BDUK 2011) within the lifetime of the current Westminster parliament.

A further problem impacting on the urban-rural digital divide is that of low levels of adoption of broadband services, where those services are available. A number of factors influence low levels of adoption, particularly demographic factors such as income, age, level of education and digital literacy (Eastin \& La Rose 2000; Dwivedi \& Lal 2007; Hauge \& Prieger 2010), all of which are associated with rural regions (Horrigan 2009). These barriers to adoption are exacerbated by the high costs of connecting to broadband services in remote rural regions that serve to perpetuate the urban-rural digital divide.

\subsection{Rural Businesses' Use of Broadband}

Rural areas in the UK attract incomers who either bring their businesses with them when they relocate or set up their own businesses following their move, investing different forms of capital into rural communities (Bosworth \& Glasgow 2012). In fact, in rural areas small businesses predominate, typically with no or few employees and little focus on business growth (Moyes et al. 2012) - self-employment is more common in rural than in urban areas in the UK, and average business sizes are smaller. For rural business owners, broadband is essential in order to communicate with peers and clients, market one's services and stay abreast of sector-relevant developments. Without broadband, rural businesses cannot compete with better-connected counterparts in urban centres. Physical isolation makes it harder to access markets and essential resources. For these businesses then, access to broadband can potentially alleviate some of the problems of this rural penalty (Skerratt \& Warren 2004) by providing opportunities to connect that can compensate for difficulties associated with distance. The use of broadband and its applications can allow businesses to create a stronger, more visible identity, advertising products and services beyond the local area. This is particularly beneficial for those business owners who do not otherwise actively network (Burgess 2008), allowing them to collaborate, for example, in order to achieve economies of scale (Moyes et al. 2012). Even though growth is not always a priority for rural business owners, research evidence suggests that there is higher growth amongst rural businesses with broadband compared to those without (Stenberg et al. 2009).

This paper reflects on a variety of business types in rural areas, with a particular focus on the creative industries. In defining the creative industries, we reference the Department of Culture, Media and Sport's (DCMS) definition as

activities which have their origin in individual creativity, skill and talent, and which have the potential for wealth and job creation through the generation and exploitation of intellectual property. These ... include the following key sectors: advertising, architecture, the art and antiques market, crafts, design, designer fashion, film, interactive leisure software, music, the performing arts, publishing software and television and radio. (DCMS Creative Industries Task Force 1998, p. 10)

The creative industries are a growing sector in rural areas of the UK - creative practitioners are increasingly attracted to the countryside as a place of inspiration and reflection (White 
2010). Creative and cultural practices contribute to the quality of life of rural residents, as they allow the expression of identity and social cohesion (European Commission 2009; Kazana \& Kazaklis 2009). Broadband connectivity is increasingly crucial for creative practitioners (Bell \& Jayne 2010).

As presented in the following, our findings support the argument that broadband connectivity is critical for the sustainability and success of rural business owners, as well as being crucial for their participation in other areas of rural community life. In the following sections, we present our methods and discuss our findings.

\section{Methods}

This paper describes research carried out with SME owners in 2012 in rural regions across Scotland, namely in Aberdeenshire and in the Highlands and Islands region. The research took a qualitative approach, performing in-depth semi-structured interviews with 15 rural practitioners. The interviewees were recruited through snowball sampling, with 12 interviewees falling into the creative industries sector, 1 interviewee working in marketing, 1 running online tutoring and 1 working in sales of crafting materials. Although it was not initially part of the sampling strategy, the creative industries focus was developed shortly after interviews commenced. This is because the majority of the interviewees who came forward were working within the creative industries. According to our sampling criterion, all interviewees experienced either poor or no Internet connectivity, and, according to the interviewees, although the businesses varied in age, all businesses had been established after the Internet had become ubiquitous for business use. Although some interviewees had not thought to investigate their Internet connection before moving home or workplace, many had checked with ISPs and been incorrectly informed that connectivity was good. Others moved when connectivity was comparable to other areas, but have since fallen behind as Internet speeds have improved more rapidly in urban areas. All of our interviewees represent very small businesses, either as sole traders or with very few employees. Interviewees were varied in terms of age and length of time they had lived in the rural region - some were native to the area, but the majority (11 out of the 15 interviewees) had relocated there (often from urban areas) at some point.

The interviews asked questions that sought to explore the ways in which rural business owners were using the Internet, experiences concerning their Internet provision; in particular, ways in which poor connectivity was holding them back, and the mediating role of broadband in participating within their local communities. Interviews mostly took place in the home or workplace of the interviewees, although some took place in mutually agreed public places such as coffee shops.

Ethical approval for the study was received from the University of Aberdeen ethical review committee. Informed voluntary consent was obtained from all interviewees prior to their participation in the study and participants knew that they could withdraw from the study at any time. Interview data were transcribed and managed in QSR Nvivo. Framework analysis was used, an approach which allows for analysis across several researchers (Spencer \& Ritchie 1994). The analysis was guided by a pre-existing thematic framework whose development was based on our reading of the literature as well as responding to themes that emerged during the interviews. The following section presents and discusses our findings. 


\section{Results and Discussion}

In this section we present findings from the research relating to the role of broadband Internet in remote rural places. Our analysis is structured in two parts which directly address the themes of the paper in relation to remote rural places - firstly, the role of broadband Internet; secondly, the impacts of (adequate and inadequate, as perceived by the interviewees) connectivity on remote rural places.

\subsection{The Role of Broadband in Remote Rural Places}

The business owners described a number of important roles that broadband Internet played, some of which were fulfilled with the available connectivity ('low bandwidth'), others ('high bandwidth') often unfulfilled for those with poor connectivity. An important low-bandwidth role of the Internet is communications via email and social media with colleagues, suppliers and clients. Such communications serve purposes relating to sales, information and research, arranging meetings and so on. However, our interviewees revealed other important functions of communications which related to their remote rural position, particularly in terms of keeping up to date with urban-centred developments in their particular field: 'I do keep in touch with what's going on in the cities, I don't want to become left behind. I want to know what the current scene is' (Interviewee 3). Living and working remotely can leave individuals feeling professionally isolated, placing a higher value on digital connectivity: 'it just would be nicer to have better connectivity and know what we are all doing because we all inspire each other, don't we?' (Interviewee 6).

Social networking in particular is key here - of value not only for expanding business networks, but also for dealing with feelings of professional and social isolation experienced in remote locations, allowing interviewees to stay up to date with developments/opportunities in their sector as well as acting as a form of market research, with many receiving useful feedback. Even these low-bandwidth uses of the Internet were difficult for those with very limited connectivity. For all the interviewees, there was a need to create a strong online identity to promote themselves widely. Some interviewees have a website, although updating this can be problematic with poor connectivity. Websites are particularly important to the creative practitioners, who feel it is essential to have a professional online presence. Clients in the creative industries expect to be able to view the standard of service/ work online - although this can be true for all sectors providing products and services, the work of the creative industries lends itself particularly well to promotion online. Even email newsletters and blogs prove difficult on a low bandwith connection if they contain anything more than text - image files or files with embedded images are often too large to be uploaded.

Digital literacy and skills were also a problem in this respect. Many of those interviewed had low levels of skill and confidence, characteristic of rural areas (Townsend et al. 2013). A number of high bandwidth broadband requirements for business or personal/lifestyle purposes were identified by interviewees, despite the fact that they were largely unable to use them. Of particular importance here is the ability to upload large data files (such as images and videos) to promote one's work, an ability to communicate via Voice over IP (VoIP) applications such as Skype, particularly crucial when at a large physical distance from collaborators, and also of great social importance for those 
physically and socially isolated from significant others: 'both my children are up and left now so things like Skype transforms your life. Skyping sometimes works but Skype can be really bad' (Interviewee 4 ).

The streaming of online content is increasingly popular for business research purposes (as well as for leisure and family time), as with this interviewee who, referring to researching the competition in the field of music video production, argues:

I want us to be able to see Youtube whenever we want, I want it to be fast ... I want to be able to use it on my television set so that we can just function like the rest of the country. (Interviewee 2)

Lower bandwidth applications also play an important role in social and community life in remote rural places: 'if you ask my daughter who went to school on Islay [neighbouring island] ... she thought it was pretty bloody remote. So her social interactions were fairly reliant on [online] social media' (Interviewee 9). Indeed, many of the interviewees talked about the importance of broadband for their children:

My daughter wants to do lots of CBeebies stuff and one of those building animal zoos and things, everything is so slow and it's such a shame. Glow [online platform used by schools as a teaching resource] - she can't get onto all of it ... she sits there for hours and waits for it and that's pretty sad. (Interviewee 2)

This illustrates how poor connectivity in remote areas may disadvantage communities educationally, further exacerbating low levels of digital efficacy in rural areas and disadvantaging children in comparison with those in better-connected areas. Disadvantages such as these may generate a new dimension of social exclusion that transcends conventional 'causes' of disadvantage such as low income.

This section has illustrated the important role of broadband connectivity for those living and working in remote rural areas - particularly in relation to business activities, although we have also reflected on social uses. The following section considers in more detail the impacts of poor connectivity that prevents such activities.

\subsection{Impacts of Broadband Connectivity for Remote Rural Places}

All but one of our interviewees perceived the connectivity as inadequate at the time of interview. ${ }^{3}$ This is problematic in a number of ways relating to their business needs as outlined in the previous section, for example in provision of timely responses to potential clients and developing skills in using web applications. Basic communication online is absolutely crucial for business owners: 'I don't have very good coverage at all with my mobile phone and as technology becomes more and more essential and everyone has to be available $24 / 7$, that does put me at a very serious disadvantage' (Interviewee 3). Some are able to work around connectivity problems, but at high costs to time and productivity: 'I make sure I check my e-mail at least once a day but that does involve me driving six miles down the track' (Interviewee 1). The creative practitioners have a greater need for high bandwidth due to demands to deliver their products online, often consisting of large data files. This is a particular requirement of media-based businesses such as film-makers: 'to give someone a preview you have to upload stuff, the only way I can realistically do that 
is I upload it in lower quality so you get blobby visual, slightly blurry film which makes something look worse' and

suddenly if you start to say, 'actually, I can do this for you but you might have it for the end of tomorrow', instead of the end of today. So they'd think, 'well why would I want to do that? I want it today ... it's like if you can't even send me a file quickly, do they really know what they are doing? (Interviewee 10)

Of our 15 interviewees, 11 are in-migrants to rural areas, who moved in search of a better quality of life, bringing their existing businesses with them or setting up new businesses. As mentioned previously, these were largely unaware of connectivity issues before they arrived in their new home (although some had checked with ISPs and were led to believe that connectivity would be good). One interviewee explains that, given adequate technology, it is possible to run a small business from anywhere: 'it doesn't really matter where you live as long as you've got the technology' (Interviewee 5). But many of the interviewees are struggling to survive in the more remote locations with inadequate (or complete lack of) broadband and express that if connectivity does not improve, they may have to relocate in order to sustain their businesses; for example: 'if we don't get improved broadband you'd have to make the decision ... we'd have to move, we'd have to leave and go to Glasgow' (Interviewee 10) - Glasgow being the nearest urban hub for this particular interviewee. For some, decisions to move to a rural area had been based on connectivity having been adequate at the time, but consequently the technology had failed to keep up with urban locations:

I chose to come here. When I chose to come here, broadband arrived. It was instrumental in our decision to come here that there would be broadband and therefore that we weren't ... if there hadn't been broadband on offer, I don't think I would have considered it. But as the broadband has stood still over seven years ... [business] possibilities have gradually diminished. (Interviewee 9)

The potential out-migration of business owners due to poor connectivity has obvious implications for the sustainability and development of remote rural regions. The complexity of potential impacts is illustrated in the following quote:

within the next few years if we don't see any changes in this sort of thing then we will have to move to somewhere which is more accessible ... which also has a knock on effect to local schools ... if you start losing people who are working within the community and stuff, it becomes a dying area - or an area just full of one type of people, it would just be farmers in the area ... and it also stops diversity and I always think diversity is the best thing for any area. Bringing in different people with different talents and different skills and then everyone feeds in what they've got and I think it's a bit depressing if you turn it into a one employment strand which will eventually happen if you are not giving opportunities or the only people left are people who have never learnt to access these technologies so maybe you will end up with a very high population of older people or a very high population of people who are not working. That is not good for any society or community. (Interviewee 2) 
This is further expressed by another interviewee who had managed to find a solution to her poor onnectivity problems by installing satellite broadband: "Absolutely crucial [to the business]. If we hadn't had a solution we would have had to have moved from here, the business part of it and that would have had repercussions on people's jobs and everything else' (Interviewee 7). This interviewee has successfully solved the problems of poor connectivity, at least for the time being - but many of our other interviewees are facing hard decisions regarding their futures in their remote rural locations. Other interviewees, when asked about the potential of satellite broadband, perceived it to be too costly for them.

\section{Conclusions}

This paper has presented findings from our research that illustrate the critical role of broadband connectivity in remote rural places. The findings show that broadband has value in providing access to a range of tools, which are particularly useful to rural businesses given the challenges associated with remoteness. We suggest that some business sectors may be becoming more dependent upon broadband connectivity than others; for example creative practitioners working from rural areas who increasingly are expected to deliver their products and services (often large data files such as high-definition video) over the Web - something requiring higher bandwidth than applications such as email. Although the majority of our sample work within the creative industries, we did also find that connectivity is crucial for those in other sectors too. We therefore argue, in line with Skerratt and Warren (2004), that connectivity is becoming increasingly important for all businesses, illustrating areas of disadvantage for those businesses with inadequate broadband connectivity. To survive, rural businesses need to develop a strong online identity to reach a wider market, be party to opportunities and important developments within their sector and find potential areas of collaboration. Social networking offers a platform to draw on existing social capital to build economic capital, representing a major area of potential for rural economies.

Although our analysis has focused on how poor connectivity impacts at the business level, we have also reflected on the importance of broadband for wider personal and social uses, and the potential broader knock-on effects of poor connectivity to the communities within which our business owners are currently embedded. For these practitioners to remain in, and thrive in rural areas and contribute effectively to their local economies and communities, they need to be able to access the tools enabled by adequate broadband. Better connectivity in rural areas is essential if such areas are to remain economically and socially sustainable. Despite movements by UK Government to improve the technological landscape in rural areas, these have as yet failed to deliver on their promise. We argue that better connectivity in remote rural places should be placed higher on the agenda in order to protect their sustainability. This is crucial both for the sustainability of rural economies and communities now and in terms of future proofing. Rural businesses need to continually develop in order to remain viable - in order for them to do so effectively, rural broadband infrastructure must also continually develop in accordance with the rest of the UK.

\section{Funding}

This research is supported by the award made by the RCUK Digital Economy theme to the dot.rural Digital Economy Hub, award reference: EP/G066051/1. 


\section{Notes}

1 We acknowledge too that there are often positive implications, particularly for businesses identifying with rurality and remoteness.

2 A connection speed of $2 \mathrm{Mbps}$ is the minimum Internet speed commonly referred to as required for broadband connectivity. Many contemporary applications of broadband Internet, such as video streaming, are not achievable at speeds below 2 Mbps (Townsend et al. 2013).

3 Researchers were only made aware of the improvements to this interviewee's connectivity upon arrival for the interview.

\section{References}

BDUK. (2011) Programme Delivery Model. Report. Available at: http://www.culture.gov.uk/images/publications/ BDUK-Programme-Delivery-Model-vs1-01.pdf (accessed 18 June 2013).

Bell, D. \& Jayne, M. (2010) The creative countryside: policy and practice in the UK rural cultural economy, Journal of Rural Studies, vol. 26, no. 3, pp. 209-218.

Blanks Hindman, D. (2000) The rural-urban digital divide, Journal \& Mass Communication Quarterly, vol. 77, no. 3, pp. 549-560.

Bosworth, G. \& Glasgow, N. (2012) Entrepreneurial behaviour among rural in-migrants, in: M. Shucksmith, D. L. Brown, S. Shortall, J. Vergunst \& M. E. Warner (eds) Rural Transformations and Rural Policies in the UK and US, pp. 138-155 (Routledge: Routledge Studies in Development and Society).

Burgess, S. (2008) England's rural areas: steps to release their economic potential. Advice from the Rural Advocate to the Prime Minister. CRC67. Cheltenham: Commission for Rural Communities.

DCMS Creative Industries Task Force. (1998) Creative Industries: Mapping Document (London: DCMS).

Dwivedi, Y. \& Lal, B. (2007) Socio-economic determinants of broadband adoption, Industrial Management and Data Systems, vol. 107, no. 5, pp. 654-671.

Eastin, M. S. \& La Rose, R. L. (2000) Internet self-efficacy and the psychology of the digital divide, Journal of Computer Mediated Communication, vol. 6. Available at: http://jcmc.indiana.edu/vol6/issue1/eastin.html (accessed 18 June 2013).

European Commission. (2009) DG-INFSO COM(2009)184 final, 20.04.2009.

Falk, I. \& Kilpatrick, S. (2000) What is social capital? A study of interaction in a rural community, Sociologia Ruralis, vol. 40, no. 1, pp. 87-110.

Hauge, J. A. \& Prieger, J. E. (2010) Demand-side programs to stimulate adoption of broadband: what works? Review of Network Economic, vol. 9, no. 3. doi:10.2202/1446-9022.1234

Horrigan, J. (2009) Home Broadband Adoption 2009 (Washington, DC: Pew Internet \& American Life).

Kazana, V. \& Kazaklis, A. (2009) Exploring quality of life concerns in the context of sustainable rural development at the local level: a Greek case study, Regional Environmental Change, vol. 9, no. 3, pp. 209-219.

Moyes, D., Whittam, G. \& Ferri, P. (2012) A conceptualisation of the relationship capital of rural small service firms, Local Economy, vol. 27, no. 2, pp. 136-151.

Ofcom. (2011) Communications Market Report: UK. Report.

Ofcom. (2013) The Availability of Communications Services in the UK. Available at: http://stakeholders.ofcom. org.uk/market-data-research/market-data/economic-geography/ (accessed 18 June 2013).

Putnam, R. (1993) Making Democracy Work: Civic Traditions in Modern Italy (Princeton, NJ: Princeton University Press).

Royal Society of Edinburgh. (2010) Digital Scotland. Report. Available at: http://www.royalsoced.org.uk/cms/ files/advice-papers/inquiry/digitalscotland/Digital\%20Scotland\%20(med\%20res).pdf (accessed 18 June 2013).

Skerratt, S. \& Warren, M. (2004). Broadband in the countryside: the new digital divide. EFITA 2003 Conference, 5-9 July 2003, Debrecen, Hungary.

Spencer, L. \& Ritchie, J. (1994) Qualitative analysis for applied policy research, in: A. Bryman \& R. G. Burgess (eds) Analysing Qualitative Data, pp. 305-329 (London: Routledge).

Stenberg, P., Morehart, M., Vogel, S., Cromartie, J., Breneman, V. \& Brown, D. (2009) Broadband Internet's Value for Rural America. United States Department of Agriculture, Economic Research Service Report, Danish Soil Association, Copenhagen, pp. 42-51.

Townsend, L., Sathiaseelan, A., Fairhurst, G. \& Wallace, C. (2013) Enhanced broadband access as a solution to the social and economic problems of the rural digital divide, Local Economy, vol. 28, no. 6, pp. 580-595. 


\section{L. Townsend et al.}

Townsend, L., Wallace, C., Smart, A. \& Norman, T. (2014). Building virtual bridges: How rural micro-enterprises develop social capital in online and face-to-face settings, Sociologia Ruralis. doi:10.1111/soru.12068

White, P. (2010) Creative industries in a rural region: Creative West: the creative sector in the Western Region of Ireland, Creative Industries Journal, vol. 3, no. 1, pp. 79-88. 